\title{
Análise de informações para gestão de relacionamento com alunos em instituição de ensino superior
}

\author{
Recebido em 26/08/2010. Aceito em 15/02/2011.
}

Auri Luiz Morais Rodrigues Filho, M.Adm.

Diretor Superintendente e Mestre pela PUCRS

auri.filho@ribeirojung.com.br

Leonardo Rocha de Oliveira

Professor e Pesquisador da PUCRS

leo.oliveira@pucrs.br

A quantidade de Instituições de Ensino Superior (IES) no Brasil mais do que dobrou no período entre 1999 e 2009. A competição no setor tem exigido estratégias de gestão contemplando a captação, manutenção e reintegração de alunos em cursos de graduação, pós-graduação e extensão. O objetivo deste trabalho é identificar informações estratégicas para uso em sistemas de gestão de relacionamento com alunos em Instituições Privadas de Ensino Superior (IPES). O trabalho envolve pesquisa exploratória e qualitativa, desenvolvida por entrevistas semi-estruturadas com profissionais que atuam em áreas de relacionamento com alunos em IPES. Resultados do trabalho indicam três grupos e 31 itens de informação estratégica a serem prioritariamente gerenciadas pelo sistema, e as áreas das IPES onde são mais usadas. Conclusões do trabalho descrevem o potencial de sistemas para Gestão de Relacionamento com Clientes (CRM) para gestão desta informação e seu papel no negócio.

Palavras-chave: Gestão de Relacionamento com Clientes; Gestão de Instituições de Ensino Superior; Gestão de Relacionamento com Alunos.

The amount of Undergraduate Institutions in Brazil has more than doubled from 1999 till 2009. Competition in this sector has driven management strategies for enrolling, keeping and reintegrating students for graduated courses. This work aims at identifying strategic information for students' relationship management systems in Private Undergraduate Institutions (PUI). The work involved a qualitative and exploratory research, developed by interviewing professionals who work in areas of students' relationship of PUI. The interviews were based on a script built from a literature review on issues as undergraduate institutions management and Customer Relationship Management (CRM) systems. Results of this work allowed the identification of three groups of strategic information, with 31 main items that should be managed by the system and the PUI areas that use them mostly. Conclusions taken from this work shown system's potential for managing such information and its business' role. 
Keywords: Customer Relationship Management; Management of Undergraduate Institutions; Students Relationship Management.

\section{INTRODUÇÃO}

A educação superior privada no Brasil sofreu uma expansão significativa na quantidade de Instituições de Educação Superior (IES) no período entre 1999 e 2006. No entanto, no período entre 2006 e 2009 as taxas de crescimento diminuíram significativamente, inclusive atingindo um resultado negativo de 1,2\% entre os anos de 2007 e 2008 (INEP, 2010). Devido a transformações e fatores como a estabilização da economia no país e diminuição nos investimentos públicos para incentivo ao crescimento das taxas de acesso da população ao ensino superior, a competição entre IES acirrou-se (MORSOLETO, 2010). No caso das Instituições Particulares de Ensino Superior (IPES), a permanência no mercado passou a depender quase que exclusivamente do pagamento de mensalidades pelos alunos, acirrando a concorrência no setor (INEP, 2010, MORSOLETO, 2010).

Os números disponibilizados pelo INEP (2010) mostram esta concorrência, especialmente entre as IPES. Na análise dos dados disponíveis dos últimos anos, observa-se um crescimento de $78,2 \%$ (de 1.004 para 1.789) no número de novas IPES, entre 2004 e 2008. A ameaça à rentabilidade e posicionamento de mercado das IPES é reforçada pelo crescimento no número de matrículas entre as mesmas, atingindo $65,2 \%$ (de 1.807.219 para 2.985.405), valor inferior ao número de novas IPES no mesmo período. Como resultado, há uma crescente disputa por alunos (clientes) capacitados a pagar pela sua formação.

A acirrada competitividade no mercado de ensino superior torna necessária a adoção de estratégias capazes de captar, manter e garantir a permanência de alunos na instituição (SONNEBORN, 2004). Portanto, tal como em vários outros setores do mundo globalizado dos negócios, não se permite mais que gestores possam descansar sobre os ganhos do passado. É necessário que as IPES despertem para as mudanças decorrentes da crescente globalização da economia dos últimos anos, tal como ocorre em outros segmentos. A transição de uma economia baseada em produtos para uma economia baseada em serviços pressupõe não apenas uma mudança de mercado, mas também exige novas habilidades e posturas gerenciais destas instituições (CARVALHO, 1997). Portanto, é preciso estar atento ao presente e inovar para poder competir e sobreviver no futuro.

Algumas IPES ainda relutam em enfrentar seu posicionamento na sociedade como empresas de negócios, embora utilizem modelos tradicionais para gestão operacional e estratégica. A complexidade e a natureza das atividades das IPES criam um ambiente específico e diferente das demais organizações empresariais. No entanto, existem analogias com as demais empresas prestadoras de serviços, onde as IPES podem ser consideradas como empresas que oferecem profissionais (exalunos) ao mercado, como produtos, com competência para se inserir na sociedade e na disputa por melhores condições de trabalho e remuneração. Portanto, os alunos são o produto e devem também ser vistos como os clientes deste tipo de empresa (FERNANDES, 1998, HANSEN, 2001). De outra forma, os alunos podem ser considerados como os clientes da Instituição de Ensino, ao passo que adquirem e utilizam os serviços por ela prestados. 
Para o desenvolvimento deste trabalho foi adotada a definição citada por Mezomo (2004), na qual os clientes das IES são os alunos que nela estudam. Seja qual for a dimensão em que se considere o cliente, é importante reconhecer que a IPES deve estar voltada para ele, visto que "não há IES que sobreviva se as expectativas de seus clientes não forem ouvidas, interpretadas e atendidas" (TACHIZAWA; ANDRADE, 2003). Em um mercado em que a prospecção de clientes está cada vez mais disputada e a fidelização é uma condição importante para a educação continuada, a gestão do relacionamento com o cliente deve passar a ser vista como prioridade (BRAGA, 2004).

A Tecnologia de Informação ( $\mathrm{TI})$ e sistemas para Gestão de Relacionamento com Clientes (CRM ou Customer Relationship Management) têm exercido papel de destaque em atividades de captação e fidelização de clientes. Princípios básicos de CRM sustentam a necessidade de identificar, diferenciar (por seu valor e necessidade) e interagir com o cliente para estabelecer uma relação de aprendizado contínuo e poder oferecer um atendimento personalizado, que seja satisfatório tanto para o cliente quanto para a empresa. Estes princípios são também aplicáveis a empresas como IPES.

CRM é uma estratégia ampla de um processo de aquisição, retenção e fidelização de clientes selecionados, com objetivo de criar valor agregado para a empresa e para o cliente (DORNELAS; XAVIER, 2003). Envolve a integração do marketing, de vendas, do atendimento ao cliente e das funções da cadeia de fornecedores da organização, para atingir o melhor resultado na oferta de valor ao cliente (PARVATIYAR; SHETH, 2002). Portanto, estratégias para venda de produtos ou serviços complementares, captação ativa de clientes, planos de fidelização, gestão pela qualidade total e satisfação de clientes passam a fazer parte do dia a dia de IPES. No entanto, o setor ainda não está se beneficiando do potencial de sistemas CRM para aprimorar esse relacionamento (BRAGA, 2004).

Este trabalho contempla a realidade da crescente competitividade entre IPES no Brasil, abordando a necessidade por um melhor atendimento ao aluno/cliente, com objetivo de atrair, reter e torná-lo leal, com base nas perspectivas oferecidas por CRM. O objetivo geral deste trabalho é de identificar as informações estratégicas para gestão de relacionamento com clientes em IES. Para isso foram entrevistados gestores de IES buscando identificar as áreas de relacionamento com clientes que causariam maior impacto sobre o sucesso da aplicação de sistemas para CRM.

\section{COMPETITIVIDADE EM INSTITUIÇÕES DE ENSINO SUPERIOR}

Como IES entende-se um tipo de organização que desenvolve uma atividade bastante peculiar que exige práticas de gestão específicas. Seu principal negócio é a formação profissional, com atividades de ensino e educação para disseminação do conhecimento, atendendo a demandas de suas comunidades internas e externas (LOPES, 1999). IES possuem objetivos gerais que são comuns a outras instituições, tais como a promoção do aprendizado, da cultura, do desenvolvimento sócioeconômico do país e das condições de vida da sociedade (PIAZZA, 1997). IES também possuem objetivos com metas a cumprir, necessitam formular estratégias para alcançar resultados e precisam de aperfeiçoamento constante em seus processos de gestão. O grande desafio que se impõe aos gestores de IPES está em 
conseguir atender a todas estas exigências qualitativas e, ao mesmo tempo, obter resultado econômico nas organizações que dirigem (ANDRADE, 2003).

A gestão de uma IPES passa pela definição de estratégias que devem atender às necessidades do negócio e também buscar caminhos para novas oportunidades que venham a qualificar as atividades já desenvolvidas. Aspectos específicos de IPES não impedem que sejam adotados modelos de gestão comumente adotados pelas demais organizações, desde que o processo decisório esteja baseado em critérios que considerem as suas características e, ao mesmo tempo, as pondere com indicadores claros e precisos relativos à sua missão como instituição de ensino (LOPES, 1999).

Outra característica que tem se apresentado como uma forte influência no setor é que o sistema de ensino superior privado tem experimentado uma forte expansão nos últimos anos. A Tabela 1 destaca o aumento do número total de IES de $125,2 \%$ entre 1995 e 2004 . Porém, vale ressaltar que este aumento de novas IES perdeu força a partir de 2003 (13,6\%) e foi menor ainda em 2004 (8,3\%), refletindo uma queda no crescimento da demanda dos anos anteriores. Esta diminuição no total de IES foi ainda maior no período entre 2006 e 2009, inclusive atingindo resultado negativo em 2008.

Dados do INEP (2010) indicam que o número total de matrículas no ensino superior acompanha o crescimento no total de IES (136,6\% entre 1999 e 2004). Este volume foi determinado principalmente pela pressão de demanda decorrente da expansão do ensino médio no período, sendo que este valor caiu para $7,1 \%$ no período entre 2004 e 2009 (INEP, 2010, MORSOLETO, 2010). Cabe também destacar o aumento contínuo da participação das IPES na quantidade total de matrículas anuais, as quais foram responsáveis por $71,7 \%$ do total em 2009 (INEP, 2010).

As IPES foram fortemente afetadas pelas mudanças ocorridas na economia nos últimos anos e têm suas receitas quase que exclusivamente dependentes das mensalidades cobradas dos seus alunos. Diante disso, as IPES buscaram alternativas de aumento de receita real, com base em fatores como a ampliação da oferta de novos cursos (de graduação e pós-graduação), prestação de serviços e parcerias com demais entidades públicas e privadas para cursos de formação profissional, realizados até mesmo dentro das próprias empresas parceiras (SONNEBORN, 2004).

Outra informação pertinente ao setor é apresentada pelo Censo de Educação Superior de 2008 (INEP, 2010), no qual 58,9\% dos alunos da educação superior estão matriculados em cursos noturnos. Isto reflete a realidade sócio-econômica no Brasil, onde cada vez mais os alunos da educação superior trabalham paralelamente a realização do curso. Isto sugere que esse perfil de aluno custeia seus próprios estudos, sendo extremamente sensível ao preço do serviço e muito exigente com a qualidade do mesmo. 


\begin{tabular}{|l|l|l|l|l|l|l|}
\hline Ano & $\begin{array}{l}\text { Total de } \\
\text { Instituições }\end{array}$ & $\%$ & $\begin{array}{l}\text { Instituições } \\
\text { Públicas }\end{array}$ & $\%$ & $\begin{array}{l}\text { Instituições } \\
\text { Privadas }\end{array}$ & $\%$ \\
\hline 1994 & 851 & - & 218 & - & 633 & - \\
\hline 1995 & 894 & 5,1 & 210 & $-3,7$ & 684 & 8,1 \\
\hline 1996 & 922 & 3,1 & 211 & 0,5 & 711 & 3,9 \\
\hline 1997 & 900 & $-2,4$ & 211 & 0,0 & 689 & $-3,1$ \\
\hline 1998 & 973 & 8,1 & 209 & $-0,9$ & 764 & 10,9 \\
\hline 1999 & 1.097 & 12,7 & 192 & $-8,8$ & 905 & 18,5 \\
\hline 2000 & 1.180 & 7,6 & 176 & $-9,1$ & 1.004 & 10,9 \\
\hline 2001 & 1.391 & 17,9 & 183 & 3,8 & 1.208 & 20,3 \\
\hline 2002 & 1.637 & 17,7 & 195 & 6,1 & 1.442 & 19,4 \\
\hline 2003 & 1.859 & 13,6 & 207 & 5,8 & 1.652 & 14,6 \\
\hline 2004 & 2.013 & 8,3 & 224 & 7,6 & 1.789 & 8,3 \\
\hline 2005 & 2.165 & 7,5 & 232 & 3,4 & 1.933 & 7,4 \\
\hline 2006 & 2.270 & 4,8 & 236 & 1,7 & 2.034 & 5,0 \\
\hline 2007 & 2.281 & 0,4 & 239 & 1,3 & 2.042 & 0,4 \\
\hline 2008 & 2.252 & $-1,2$ & 241 & 0,8 & 2.011 & $-1,5$ \\
\hline 2009 & 2.314 & 2,7 & 245 & 1,6 & 2.069 & 2,8 \\
\hline \multicolumn{7}{r}{ Tabela 1- Evolução número de IES (1994-2009) } \\
\hline
\end{tabular}

A atual realidade de IPES indica ter chegado ao fim o crescimento da demanda por matrículas. A gestão destas instituições não pode mais repetir os erros e $\mathrm{o}$ amadorismo de gestão de décadas passadas. Gestores precisam formar empresas organizadas e com visão de futuro (BRAGA, 2004), onde somente "sobreviverão e vencerão as instituições que forem mais bem administradas, voltadas ao mercado a que servem, e com uso de práticas modernas de gestão" (CARVALHO, 1997).

O êxito de uma IPES no cumprimento de sua missão é a formação de profissionais com um conjunto de habilidades, competências e conhecimentos, valorizados e reconhecidos pelos mercados que os contratam. Para que isto ocorra, as IPES devem continuamente avaliar os resultados obtidos com a formação de seus alunos como profissionais e as expectativas do mercado. É necessário pesquisar e aferir, junto aos contratantes, o perfil e os atributos do profissional desejado. Ao mesmo tempo, é preciso consultar o aluno formado em relação ao seu desempenho. Unir com sucesso os interesses dos alunos aos objetivos definidos no plano estratégico e projeto pedagógico, garantindo a integração entre instituição e cliente, torna-se ponto chave na obtenção de resultados que assegurem a missão e sobrevivência da instituição (TACHIZAWA; ANDRADE, 2003).

Em todos os setores econômicos, a gestão do relacionamento com clientes e potenciais clientes é cada vez mais uma prioridade na agenda das empresas. É importante constituir canais de comunicação personalizados para gerenciar o relacionamento e manter o cliente informado, participante e encantado com a empresa (BRETZKE, 2000). Por outro lado, o setor do ensino superior no Brasil parece estar ainda distante das ações de vanguarda no que se refere ao trato com seus clientes. No momento atual, em que as instituições operam com um alunado potencial cada vez menor, é fundamental para sua sobrevivência trabalhar na gestão de relacionamento com seus alunos, inclusive envolvendo a participação dos pais, instituições governamentais e empresariais. 


\section{GESTÃO DE RELACIONAMENTO DOM CLIENTES EM IES}

A crescente concorrência entre IPES tem exigido melhorias em suas diversas atividades de negócios, as quais têm como objetivo estratégico a captação de recursos a partir de seus alunos (clientes). Os clientes da educação superior, por sua vez, estão demandando mais atenção e qualidade nos serviços prestados pelas IPES. Em função desta nova realidade, IPES têm investido esforços para obter as vantagens proporcionadas pelo uso de práticas de gestão para relacionamento com clientes, por reconhecer que estes representam um dos maiores ativos de negócios. Para isso, sistemas de Gestão de Relacionamento com Clientes (CRM) tem sido uma oportunidade, pois atuam nos processos de atendimento em áreas de contato com alunos, tais como comunicação, análise de satisfação e serviços de suporte à solução de problemas. Sistemas de CRM têm seu foco na gestão de relacionamento com os clientes da empresa e devem atuar em todas as áreas de negócios em que existe o contato do cliente com a empresa (GRANT; ANDERSON, 2002).

Independente do uso da tecnologia de sistemas CRM, a prática de gestão do relacionamento com clientes pode ser vista como um processo que incorpora estratégias e iniciativas para obter um conjunto de informações sobre clientes individuais ou grupos, com o objetivo de subsidiar ações que visem à retenção e aquisição de novos clientes (DORNELAS; XAVIER, 2003). Entre as estratégias para retenção e captação de novos clientes, o CRM apresenta conceitos e estruturas pelas quais os clientes podem se beneficiar do acesso a informações e serviços. Com o advento das novas tecnologias de informação, alunos, clientes potenciais e mesmo profissionais em IPES podem ter acesso, mesmo a distância com uso da Internet, a informações que necessitam para a tomada de decisões. Outros benefícios podem ser gerados pela integração aos demais sistemas da IPES, formando um único banco de dados institucional, onde podem estar contidas as regras do negócio, os fluxos de informação entre sistemas administrativos, acadêmicos e de comunicação. Desta forma, as necessidades, direitos e deveres do cliente podem estar alinhados aos objetivos de negócios nas diversas áreas da IES (GRANT; ANDERSON, 2002).

CRM baseia-se na premissa de que os melhores clientes, seja por gastarem mais ou serem fiéis, não devem ser tratados da mesma forma que aqueles que representam menos ou causam prejuízos para a empresa. Logo, é preciso identificar os clientes que representam maior valor, para oferecer-lhes um atendimento diferenciado. Por isso, é necessário aproveitar todas as interações (momentos da verdade) que a organização tem com o cliente, no sentido de coletar dados e transformá-los em informações que possam ser disseminadas pela empresa, permitindo que todos os departamentos (contato com clientes, vendas, marketing, diretoria e outros) possam ter uma visão comum do cliente. Estas informações podem incluir dados cadastrais, seus gostos, preferências, quantas vezes ligou, reclamações que fez, sugestões que deu, grau de satisfação, quanto representa de valor para a empresa, entre outras (OLIVEIRA; RODRIGUES, 2002). Em iniciativas para fidelização, onde é esperado um aumento do número de contatos com o cliente, é ainda maior a necessidade de avaliar as reações, desenvolver respostas rápidas a questionamentos e oferecer soluções imediatas a solicitações, a ponto de transformar experiências negativas em positivas (PARVATIYAR; SHETH, 2002). 
Todas as informações relativas ao relacionamento do cliente com a empresa precisam ser compiladas ou recuperadas no momento exato em que está ocorrendo este contato. $\mathrm{O}$ cliente precisa ser reconhecido e a empresa deve aproveitar esse momento para obter mais informações, oferecer novos produtos e serviços que se encaixem ao perfil daquela pessoa em particular (PARVATIYAR; SHETH, 2002).

A transformação dos dados brutos em informações estratégicas e sua distribuição nos diferentes níveis da empresa é fator crítico para a tomada de decisões, mas exige infra-estrutura de tecnologia. Ao mesmo tempo, a integração das informações possibilita a compreensão do contexto em que o negócio está inserido, exigindo que sejam definidas as principais informações estratégicas e processos para a aplicação de CRM de forma a produzir benefícios decisivos ao negócio (SWIFT, 2001).

Também é necessário mudar a cultura da organização, seja por treinamento de funcionários ou qualquer outra forma que possibilite esta mudança. Apenas implementar tecnologias de CRM sem fazer o redesenho dos processos internos da empresa e sem criar um modelo de relacionamento e de atendimento ao cliente pode levar a um simples projeto de informatização da área de contato com o cliente, sem conduzir aos resultados esperados pela organização (GRANT; ANDERSON, 2002).

Sob a perspectiva do aluno como cliente em uma IPES, atividades de CRM permitem a interação por meio de uma única área da empresa, a qual pode ter a compreensão completa de seu perfil único. No exemplo de um estudante, isto pode ser visto como uma interação entre a admissão, registro, financeiro, secretarias de cursos, orientação de trabalhos e atendimentos em geral. Sob a perspectiva da instituição, a utilização de CRM pode fornecer um retrato atualizado e completo de cada um de seus alunos, de forma individual ou em grupos (turmas), contemplando todas as atividades que os envolvem (GRANT; ANDERSON, 2002).

Atualmente é comum que IPES trabalhem com as áreas pedagógicas e administrativas de forma independente, com a justificativa de que possuem funções e objetivos diferentes (GRANT; ANDERSON, 2002). Por oferecer uma plataforma comum de tecnologia para a comunicação e interação com o cliente, as soluções de CRM buscam eliminar as divisas organizacionais que dificultam a interação com seus clientes. Integrar as diferentes áreas de uma empresa para oferecer uma visão única e abrangente sobre seus clientes é, com efeito, um dos principais objetivos com CRM. Independente do papel da tecnologia, CRM não deve ser visto como um produto ou serviço, mas parte de uma estratégia ampla de gestão de relacionamento com clientes e benefícios ao negócio (PARVATIYAR; SHETH, 2002).

Para o sucesso com o uso de CRM é necessário que todos na empresa estejam voltados para o cliente (BRAGA, 2004). Para o autor, a postura profissional e o uso correto da tecnologia são fundamentais, devendo ser intensamente embutidos nas pessoas que compõem a organização. Na falta de processos bem elaborados, qualquer iniciativa deve fracassar em atingir seus objetivos e CRM não é exceção. As empresas devem definir seus requisitos, objetivos de negócios e desenvolver processos de CRM para atender a esses requisitos. 2004):

A utilização de CRM em IPES pode contemplar atividades como (BRAGA,

- fornecer suporte para a realização de ações de marketing de relacionamento, tais como e-mail marketing, telemarketing (ativo e passivo), promoções, parcerias, etc.; 
- coordenar e integrar ações de atendimento aos diversos clientes e potenciais clientes da instituição, percebendo as necessidades dos mesmos, visando à oferta de novos produtos e promovendo relacionamentos de longo prazo;

- coordenar, organizar e avaliar resultados de campanhas publicitárias e demais ações de comunicação da instituição;

- estruturar, filtrar e disponibilizar, em forma de relatórios ou gráficos, as informações sobre os clientes e resultados das diversas atividades da instituição;

- gerar métricas para avaliar os processos de atendimento, orientando as respostas em termos de qualidade, fidelidade, atualização e rapidez, com base nas informações registradas e estruturadas em um único banco de dados;

- gerenciar as informações sobre o processo de evasão, visando identificar os motivos e reduzir o seu percentual.

- agrupar perfis de clientes com base em segmentações demográficas, geográficas, psicográficas, etc., comunicando-se com cada grupo de forma adequada.

É importante para a implementação de CRM estabelecer o uso de métricas para o acompanhamento das políticas de relacionamento e demais processos. Desta forma é possível avaliar se estão realmente dando um retorno positivo em relação às estratégias e ações definidas. Alguns indicadores financeiros e referentes ao mercado mantêm sua importância, mesmo que objetivos de CRM estejam mais focados no relacionamento com o cliente. Alguns indicadores implicam em um melhor trabalho na captação de informações sobre o desempenho da empresa em relação ao custo de aquisição de novos clientes, taxas de conversão de clientes potenciais em alunos, taxas de retenção dos clientes (e evasão), taxas de venda de serviços e medidas de lealdade (WINER, 2001).

\section{MÉTODO E PROCEDIMENTOS DE PESQUISA}

O método de pesquisa adotado neste trabalho foi o estudo de caso, o qual é especialmente útil para investigar um fenômeno (objeto) dentro de seu real contexto de ocorrência. $O$ objetivo deste trabalho é identificar as informações estratégicas de suporte à implementação de CRM em IES. A unidade de análise (IPES) foi selecionada pela característica do teste crucial da teoria existente (YIN, 2005), especialmente a visão do aluno como o cliente, o qual deve ser visto como o foco de atenção da organização (GRANT; ANDERSON, 2002).

A instituição escolhida para análise é um Centro Universitário filantrópico, que conta atualmente com 10.300 alunos no ensino superior, distribuídos em 36 cursos de graduação e 13 de Pós-Graduação Lato Sensu. A IPES possui forte tradição na área da saúde, inclusive com seu curso de Mestrado em Saúde e Gestão Ambiental. O Centro Universitário dispõe de 9 campi no estado do RS, sendo 7 destes na cidade de Porto Alegre, 1 na cidade de Santa Maria e 1 na cidade de Uruguaiana, a $600 \mathrm{~km}$ da capital.

Para obter uma melhor compreensão e interpretação do fenômeno estudado, de maneira a proporcionar uma visão global para a formulação de pressupostos mais precisos, foi usada uma pesquisa qualitativa de natureza exploratória (YIN, 
2005). Para isso foi utilizado um roteiro estruturado com 28 questões (Apêndice A) como instrumento de pesquisa para coleta de dados primários. Este instrumento foi elaborado com base na revisão de literatura e direcionou as entrevistas com os gestores das nove áreas de relacionamento com o aluno (ARA) conforme indicado na Figura 1. Estas nove entrevistas foram realizadas dentro da IPES, em horário comercial e gravadas para futura análise. As ARA da IPES são (i) Marketing, (ii) Vestibular, (iii) Financeiro, (iv) Setor de Bolsas, (v) Coordenação de Curso, (vi) Biblioteca, (vii) Suporte de Ensino a Distância (Suporte EAD), (viii) Central de Atendimento ao Estudante (CAE) e (ix) Ouvidoria.

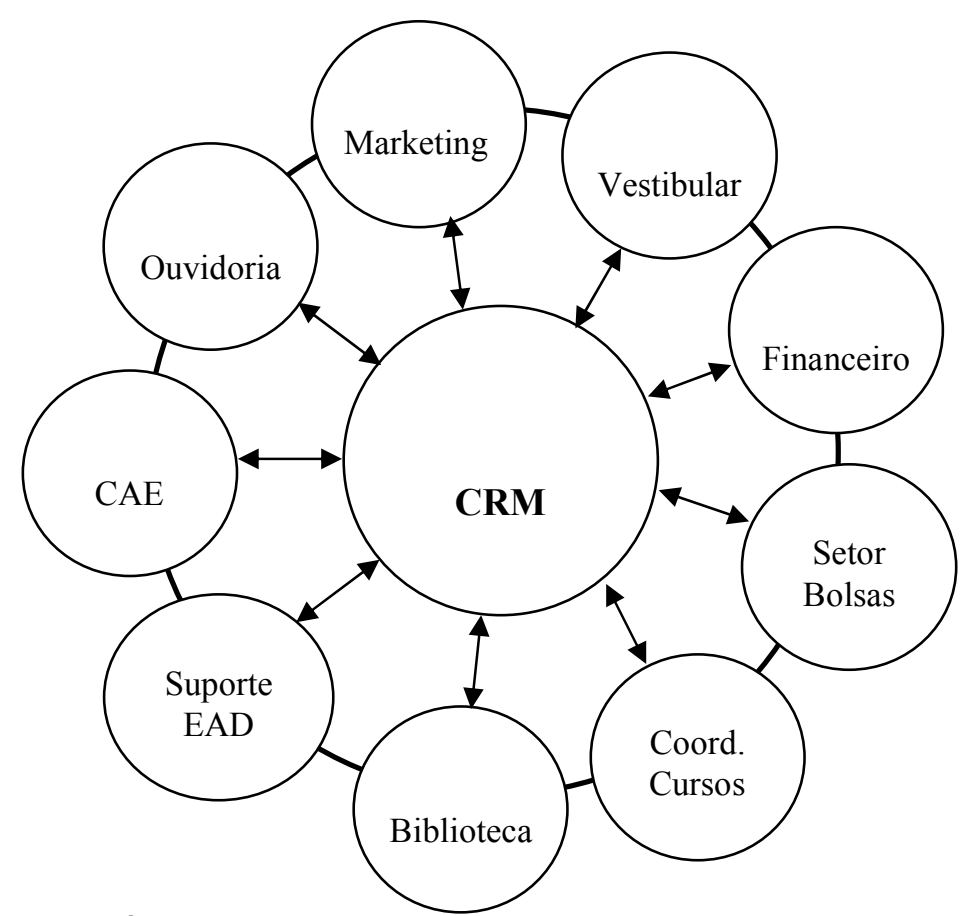

Figura 1 - Áreas de Relacionamento com Aluno (ARA) entrevistadas Fonte: Elaborado pelos autores

Antes da aplicação foi realizado um pré-teste do instrumento de pesquisa, com o objetivo de analisar a qualidade do mesmo em relação a aspectos como conteúdo, estrutura e clareza, além de treinar o pesquisador com sua aplicação. Este pré-teste foi elaborado de duas formas (COOPER; SCHINDLER, 2003):

- pré-teste com pesquisadores especialistas na área, realizado junto ao corpo docente da PUCRS, buscando comentários sobre o conteúdo e abrangência do instrumento;

- pré-teste com respondente realizado junto a profissional da IPES, com objetivo de analisar a aplicabilidade do instrumento em relação ao tempo necessário para responder à clareza das questões e à facilidade de resposta.

Após os ajustes necessários no instrumento foi realizada a primeira entrevista junto a ARA Central de Atendimento ao Estudante. Os gerentes das demais ARA foram entrevistados a seguir e o processo ocorreu sem dificuldades, visto que estes profissionais estavam avisados sobre as entrevistas e seus objetivos, inclusive contando com apoio da alta-gerência da instituição.

Para análise das entrevistas foi adotada a estratégia analítica de descrição de caso (IPES), analisando todas as evidências possíveis à luz das principais interpretações presentes na fundamentação teórica e focando nos aspectos mais significativos do fenômeno em estudo, além de considerar os conhecimentos prévios 
dos autores (YIN, 2005). O método utilizado foi análise de conteúdo temática e categorial (BARDIN, 1979), resultando em três dimensões superiores que emergiram da análise dos dados.

$\mathrm{Na}$ fase inicial de análise de resultados foi definida a fundamentação teórica para embasar todo o processo de análise, seguida da transcrição das entrevistas gravadas e uma leitura flutuante (BARDIN, 1979). Na fase seguinte de exploração do material, os dados foram codificados para auxiliar na interpretação final e categorizados a partir das codificações. Inicialmente foram obtidas oitenta e quatro (84) diferentes informações estratégicas como necessárias para a gestão de relacionamento com alunos na IPES. Este total de informações foi analisado com mais detalhes e reduzido para um total de 31, visto que muitas destas eram similares, embora indicadas de forma diferente. A seguir, estas informações foram agrupadas em três dimensões, de acordo com sua origem. Estas dimensões são: (i) Dimensão Aluno com informações sobre perfil, percepção e relação do aluno com a IPES; (ii) Dimensão IPES com informações do ambiente interno das ARA e demais setores da instituição e; (iii) Dimensão Mercado, com informações sobre o ambiente externo, tais como concorrência, potenciais clientes e possíveis parcerias.

Devido à quantidade e complexidade das informações da Dimensão Aluno (o qual foi considerada como a dimensão de maior interesse pela IPES), a mesma foi dividida em três sub-dimensões: (i.i) Perfil, (i.ii) Percepção sobre IPES e (i.iii) Relação aluno x IPES. Ao final, o número total de informações estratégicas identificadas para a IPES foi de trinta e uma, sendo dezessete na Dimensão Aluno (divididas em três sub-dimensões), nove na Dimensão IPES e cinco na Dimensão Mercado. Este resultado está apresentado no Quadro 1 e relacionado às ARA onde as informações foram indicadas.

$\mathrm{Na}$ fase de interpretação final dos resultados foi feita uma análise detalhada das trinta e uma informações estratégicas. O objetivo desta análise foi de identificar a validade e significância dos resultados. Para isso foi elaborada uma análise cruzando os resultados do Quadro 1 (informações) com a fundamentação teórica (validade nomológica); revisão do relatório final do estudo de caso por um informante-chave (YIN, 2005), o gestor da Tecnologia da Informação (validade do constructo); e a utilização de teorias em estudos de caso único (YIN, 2005) para uma validade externa.

\section{RESULTADOS DE TRABALHO}

Os resultados da pesquisa com os gestores da IPES foram tabulados de forma a gerar um mapeamento das necessidades de informações para cada uma das ARA da IPES. Estas informações são apresentadas no Quadro 1, seguidas pela discussão de cada dimensão de análise. 


\begin{tabular}{|c|c|c|c|c|c|c|c|c|c|}
\hline Categorias e Áreas & 它 & 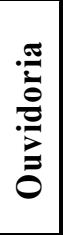 & 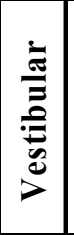 & 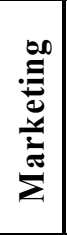 & 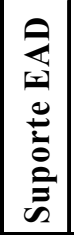 & 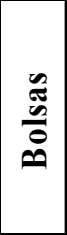 & 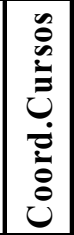 & 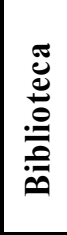 & 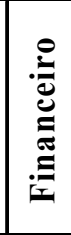 \\
\hline \multicolumn{10}{|l|}{ Dimensão Aluno } \\
\hline \multicolumn{10}{|l|}{$\begin{array}{l}\text { Sub-dimensão Perfil } \\
\end{array}$} \\
\hline \multicolumn{10}{|c|}{ Informações cadastrais } \\
\hline \multicolumn{10}{|c|}{ Disponibilidade de tempo para atividades extra-classe } \\
\hline \multicolumn{10}{|l|}{ Nível de habilidade física / cognitiva } \\
\hline \multicolumn{10}{|l|}{ Hábitos } \\
\hline \multicolumn{10}{|l|}{ Índice de carência } \\
\hline \multicolumn{10}{|l|}{ Informações financeiras } \\
\hline \multicolumn{10}{|l|}{ Informações sócio-culturais } \\
\hline \multirow{2}{*}{\multicolumn{10}{|c|}{\begin{tabular}{|l} 
Perfil psicológico / comportamental \\
Sub-dimensão Percepção sobre IES
\end{tabular}}} \\
\hline & & & & & & & & & \\
\hline \multicolumn{10}{|l|}{ Críticas e Sugestões } \\
\hline \multicolumn{10}{|l|}{ Expectativa dos alunos com a IES } \\
\hline \multirow{2}{*}{\multicolumn{10}{|c|}{\begin{tabular}{|l} 
Satisfação/Opinião com IES \\
Sub-dimensão Relação Aluno $x$ IES
\end{tabular}}} \\
\hline & & & & & & & & & \\
\hline \multicolumn{10}{|c|}{ Situação e motivos de adimplência } \\
\hline \multicolumn{10}{|l|}{ Histórico de desempenho } \\
\hline \multicolumn{10}{|l|}{ Fidelização do aluno (educação continuada) } \\
\hline \multicolumn{10}{|l|}{ Perfil do usuário sobre utilização da biblioteca } \\
\hline \multicolumn{10}{|l|}{ Informações de ingresso e retenção } \\
\hline \multicolumn{10}{|l|}{ Vida acadêmica do aluno } \\
\hline \multicolumn{10}{|c|}{\begin{tabular}{|l} 
Dimensão IES \\
\end{tabular}} \\
\hline \multicolumn{10}{|c|}{ Disponibilidade de informações para comunicação on-line } \\
\hline \multicolumn{10}{|c|}{ Compartilhamento de informações inter-setoriais } \\
\hline \multicolumn{10}{|c|}{ Impacto dos processos sobre o atendimento ao aluno } \\
\hline \multicolumn{10}{|c|}{ Informações sobre utilização de recursos da biblioteca } \\
\hline \multicolumn{10}{|c|}{ Indicadores de atendimento ao aluno } \\
\hline \multicolumn{10}{|l|}{ Informações financeiras segmentadas } \\
\hline Percepção do docente em relação ao aluna & & & & & & & & & \\
\hline Perfil geral segmentado dos alunos & & & & & & & & & \\
\hline Informações sobre novos produtos/serviço & & & & & & & & & \\
\hline \begin{tabular}{|r|} 
Dimensão Mercado \\
\end{tabular} & & & & & & & & & \\
\hline Informações da concorrência & & & & & & & & & \\
\hline Informações sobre prospects & & & & & & & & & \\
\hline Parcerias potenciais no mercado & & & & & & & & & \\
\hline Inserção do aluno no mercado de trabalho & & & & & & & & & \\
\hline
\end{tabular}

Quadro 1 - Informações estratégicas agrupadas em três dimensões

\subsection{Dimensão Aluno}

Esta dimensão de análise contempla 3 sub-dimensões e os resultados estão detalhados para cada uma delas. $\mathrm{Na}$ sub-dimensão Perfil as informações estratégicas que mais se destacaram para as ARA foram as de cunho sócio-cultural, tendo sido mencionadas por oito dos nove gestores entrevistados. Em segundo 
lugar, ficaram as informações relativas a aspectos financeiros da relação entre o aluno e a IPES, contemplando aspectos de avaliação patrimonial e relatórios de demonstrativos ao longo do curso e projeções de resultados. As informações cadastrais do aluno, inclusive em relação a aspectos familiares e de comportamento, também foram apontadas como de grande valia pela maior parte das áreas entrevistadas, tendo sido mencionadas por seis e cinco ARA respectivamente. Informações relativas ao perfil psicológico, habilidades físicas e cognitivas (tais como domínio no uso de computadores, práticas de atletismo e instrumentos musicais), disponibilidade de tempo para atividades extraclasse e grau de carência do aluno também foram ressaltadas pelas áreas como sendo informações importantes no entendimento geral sobre quem é o aluno, no seu contato com a instituição. Por exemplo, o grau de carência do aluno é medido por um indicador que contempla informações referentes à renda familiar, moradia, escolaridade e atuação profissional.

A análise das entrevistas indica que existe uma forte preocupação quanto ao conhecimento sobre quem é o aluno no momento do atendimento, independente da ARA que o esteja atendendo. Esta preocupação dos gestores traduz o foco da necessidade de melhoria na gestão de relacionamento com o cliente, pois coloca o aluno como centro de atenções da organização no processo de implementação de CRM (GRANT; ANDERSON, 2002). Esta centralização no aluno deve possibilitar à organização oferecer produtos e serviços de forma personalizada e de acordo com o perfil de cada aluno (PARVATIYAR; SHETH, 2002).

A análise das entrevistas também indica que o aluno não é visto como o fato gerador de lucratividade para a IPES, mas como um meio para a sustentação dos serviços oferecidos. Por ser uma instituição filantrópica, a IPES preocupa-se com informações referentes à situação financeira do aluno com o intuito de poder gerar facilidades para o ingresso e permanência na instituição. Na IPES estudada não há diferenciação no atendimento em relação ao perfil do aluno, sendo considerado inclusive como ato discriminatório por alguns gestores, apesar de alguns afirmarem que a área de conhecimento na qual o aluno está inserido é um fator de influência sobre o comportamento na relação com a IPES. Estas informações contrapõem a visão de Oliveira e Rodrigues (2002), pois apontam que um cliente mais lucrativo deve ter um atendimento diferenciado em relação a outro que representa menos para a empresa. De qualquer forma, independente da decisão sobre a forma de atendimento aos alunos, as informações sobre esta relação financeira é apontada como necessária ao projeto de CRM.

$\mathrm{Na}$ sub-dimensão Percepção do Aluno em relação à IPES (estrutura, processos e serviços oferecidos), a satisfação e a opinião do aluno foram consideradas as informações mais relevantes no relacionamento com o cliente pela maior parte das áreas analisadas, seguidas das críticas e sugestões que os alunos possam realizar em relação à IPES e aos setores envolvidos, incluindo suas reclamações, dificuldades e dúvidas. A ARA Marketing salientou ainda que a expectativa dos alunos em relação à instituição é uma informação de grande valor para direcionar o planejamento e execução de suas estratégias.

Esta preocupação com a qualidade do atendimento observada pelas diversas áreas indica que a IPES não sobrevive se as expectativas dos seus clientes não forem ouvidas, interpretadas e atendidas (TACHIZAWA; ANDRADE, 2003). Percebese na instituição estudada que escutar o cliente é um aspecto de grande preocupação, o que pode ser observado na consolidação do canal de Ouvidoria, responsável por receber questionamentos dos alunos e repassar às diversas áreas, 
fortalecendo o processo de melhoria dos serviços e do atendimento ao aluno. Quanto maior a união entre os interesses dos alunos e os objetivos do planejamento estratégico e plano pedagógico da IPES, melhores serão os resultados que irão assegurar 0 alcance da missão e sobrevivência da instituição (TACHIZAWA; ANDRADE, 2003). A análise desse conjunto de informações propicia o redesenho dos processos internos da empresa, que é fundamental para a implementação com sucesso de uma estratégia voltada à gestão de relacionamento e atendimento aos clientes (GRANT; ANDERSON, 2002) e permite detectar e gerenciar oportunidades de fidelização destes (BRAGA, 2004).

Na sub-dimensão Relação do Aluno com a IPES, a informação estratégica identificada, de forma unânime, como a mais importante para a manutenção do seu vínculo com a instituição foi a fidelização do aluno, com enfoque na educação continuada. A vida acadêmica do aluno na instituição (incluindo a quantidade de cursos realizados e a área de conhecimento estudada) mostrou-se como a segunda informação de maior importância, seguida pelo desempenho acadêmico ao longo do curso (sua evolução e freqüência aos ambientes de ensino, como o ambiente virtual), apontadas pelo representante das coordenações de curso e pela gestora de $E A D$, respectivamente. Foram ainda relatadas, por algumas ARA, outras informações consideradas relevantes, como as informações sobre a inadimplência e seus motivos, as informações de ingresso e retenção dos alunos na IPES e também o perfil dos usuários da biblioteca. Entende-se como retenção dos alunos na IPES a participação em oficinas do processo seletivo, o tempo de permanência na IPES, os motivos de evasão de alunos e os motivos de candidatos aprovados nos processos seletivos não matricularem-se nos cursos.

Percebe-se desta forma que os gestores apontam a necessidade do acompanhamento não apenas do perfil, mas da relação do aluno com a IPES a longo prazo. A necessidade de iniciar o processo de conhecimento sobre o aluno quando ele ainda é um candidato ao processo seletivo, dá maiores garantias a instituição na retenção dos mesmos, ou seja, acompanhá-lo durante sua vida acadêmica, saber das atividades que participa, monitorar seu aproveitamento, identificar os momentos de contato com as ARA e ainda, acompanhar o retorno à IPES para novos cursos após sua graduação percebendo a melhor forma de conduzi-lo na sua formação. O CRM ganha status de prioridade quando visto por este ângulo, tornando a fidelização do cliente questão imperativa frente à alta competitividade na captação de novos clientes (BRAGA, 2004). Desta forma, o marketing de relacionamento propiciará o retorno do aluno à instituição ou ele a recomendará para outros potenciais clientes, auxiliando no processo de captação de novos alunos para a IPES. O CRM, neste caso, torna-se uma ferramenta imprescindível para o acompanhamento e uso destas informações estratégicas.

Por fim, houve apenas uma referência quanto à preocupação sobre o aluno ser um bom ou um mau cliente, especificamente quanto aos seus hábitos no uso dos livros da biblioteca, no que se refere à danificação de exemplares, atrasos nas devoluções e acúmulo de débitos. De uma maneira geral, as áreas da instituição não dão relevância ao aspecto da qualidade do cliente nas relações deste com a IPES, não sendo apresentada nenhuma forma de seleção dos mesmos. Provavelmente as IPES não estejam preparadas para dar-se ao luxo de selecionar os clientes que realmente agregam valor ao negócio, recusando aqueles que não se caracterizam como bons clientes, devido à alta concorrência no mercado e à expansão crescente da oferta de cursos e vagas (SONNEBORN, 2004). Como visto anteriormente em relação ao perfil do aluno, a diferenciação do atendimento não demonstra ser um 
benefício a ser aproveitado entre as potencialidades do CRM para a IPES pesquisada, pelo menos nas condições levantadas por este estudo.

\subsection{Dimensão IES}

Na Dimensão IES, a informação estratégica apontada como de maior relevância pelos gestores foi o compartilhamento de informações inter-setoriais, sendo primordial para garantir um melhor atendimento aos alunos. Isto é reforçado pelo entendimento de que as informações disseminadas pela empresa permitem a todos os departamentos ter uma visão única do cliente (OLIVEIRA; RODRIGUES, 2002). Estas informações integradas compreendem dados sobre as coordenações de cursos, estruturas, processos e utilização de recursos das diversas áreas institucionais, além de análises geradas por pesquisas da ARA Marketing. No caso verificado, não somente as informações dos alunos captadas no momento do atendimento são importantes de serem compartilhadas entre os setores. Informações a respeito de cada um dos setores e de seus processos também precisam estar disponíveis às demais áreas, de forma a garantir a qualidade do atendimento do aluno na instituição.

O uso de indicadores para acompanhamento do atendimento do aluno e de sua satisfação em relação à IPES foi apontado pela maior parte das ARA como sendo de grande valor, permitindo visualizar informações para avaliação da qualidade dos serviços oferecidos. Exemplos de indicadores usados na IPES são o tempo médio de atendimento, tempo de retorno (resposta) ao aluno, número de atendimentos (semanais e mensais), número de contatos realizados pelo aluno e número de serviços solicitados à Central de Atendimento ao Estudante (CAE). Conforme constatado nas entrevistas com os gestores, o uso de métricas de avaliação ainda não é uma prática consolidada na IPES. Entretanto, uma das características de projetos com CRM é a criação de métricas para avaliar os processos de atendimento, orientando as respostas em termos de qualidade, fidelidade, atualização e rapidez, com base nas informações registradas e estruturadas em um único banco de dados (BRAGA, 2004). O uso de métricas é importante para que se possa avaliar de forma contínua os resultados obtidos com as políticas de relacionamento (WINER, 2001). Monitorar a relação da empresa com o cliente ajuda a estreitar o relacionamento e permite uma resposta imediata às reações negativas dos clientes (PARVATIYAR; SHETH, 2002).

Outro ponto que se mostrou relevante para cinco das nove áreas analisadas foi a possibilidade de disponibilizar informações para o auto-atendimento do aluno e algumas ferramentas de comunicação, como os Websites, para que o aluno possa buscar informações a respeito da IES e de sua vida acadêmica, além de poder manifestar sua opinião sobre a instituição. Estas necessidades do cliente (aluno) passam a ser o foco da atenção das empresas (IPES), o qual passa a contar com o suporte da tecnologia para integração dos sistemas em um único banco de dados. Isto proporciona um fluxo contínuo de informações entre diferentes setores administrativos e acadêmicos, com disponibilidade de informações que podem inclusive ser disponibilizadas na Web (GRANT; ANDERSON, 2002). Na IPES estudada observa-se esta preocupação no acesso ao portal institucional e na disponibilidade de serviços on-line ao alunado. A implementação de CRM nesta IPES consolidaria as ações neste sentido. 
Foram também destacadas por algumas ARA a necessidade de informações referentes ao impacto dos processos de cada setor sobre o atendimento ao aluno, à percepção do docente em relação ao alunado, o perfil geral dos alunos segmentado por curso e turma, as informações financeiras segmentadas por curso e região onde residem, as informações sobre novos produtos e serviços a serem ofertados ao aluno e as informações gerais sobre a utilização dos recursos da biblioteca. Estas informações denotam a necessidade por uma visão não apenas individualizada sobre cada um dos clientes, mas também uma visão global do alunado e de sua relação com as ARA da IPES. Estas informações permitem definir estratégias para oferta de produtos e serviços, baseados no perfil do público alvo, prospectado como um todo (PARVATIYAR; SHETH, 2002), possibilitando inclusive análises de tendências comportamentais dos mesmos.

\subsection{Dimensão Mercado}

As informações estratégicas categorizadas na Dimensão Mercado foram pouco abordadas pelos gestores das ARA. As informações oferecidas pelas ARA Marketing, Suporte EAD, Bolsas e Coordenação de Curso se resumiram a informações da concorrência, potenciais clientes, potenciais parcerias, inserção do egresso no mercado de trabalho e diretrizes para a oferta de bolsas. Todas estas informações visam diretamente ou indiretamente a retenção, captação e prospecção de novos alunos, em sintonia com os principais objetivos de CRM.

O conhecimento do perfil do aluno, do mercado em que a IES está inserida e a maneira como o atual e o potencial aluno se relaciona com o mercado de trabalho, antes e depois de sua passagem pela instituição, foram indicadas como informações importantes para a compreensão e definição dos processos e estratégias para captação e retenção de clientes. A relação do aluno com o mercado é visto como parâmetro para definição de métricas de avaliação das políticas de relacionamento com o cliente. Particularmente, a inserção do egresso no mercado de trabalho é um forte indicativo do papel e dos resultados da formação provida pela IES ao aluno. Isto pode ser mais facilmente visualizado se a instituição dispuser de mecanismos para acompanhar a vida acadêmica do aluno, as informações do seu perfil durante seus estudos e seu desempenho profissional, com perspectiva de longo prazo. Para Miyashita (2006), um ex-aluno deve ser cortejado pela Instituição de Ensino, pois deve ter filhos, trabalho e deve se orgulhar da escola em que estudou.

Com o aumento da concorrência no ensino superior do país e a atual redução do potencial alunado com capacidade de pagar por sua formação, a captação de novos clientes está cada vez mais competitiva. Isto leva a necessidade de adotar estratégias para prospecção e captação do cliente, bem como para retenção e fidelização a longo prazo. Para Carvalho (1997) "sobreviverão e vencerão as instituições que forem mais bem administradas, voltadas ao mercado a que servem, utilizando-se de todos os recursos disponíveis". O uso eficiente da gestão do relacionamento com o cliente pode ser o caminho para que as IPES se vejam mais como verdadeiras organizações empresariais. 


\section{CONSIDERAÇÕES FINAIS}

O objetivo deste trabalho foi de identificar as informações estratégicas para gestão de relacionamento com alunos (clientes) em IES. Este objetivo foi atingido e, com base nas informações coletadas a partir das diversas áreas de contato com alunos do caso em estudo, foram consideradas três dimensões para representar as informações estratégicas da instituição, que são: Aluno, IES e Mercado.

A Dimensão Aluno mostrou-se como a mais significativa para as ARA e com a maior quantidade de informações estratégicas relacionadas (17). Estas informações foram divididas em três sub-dimensões referentes (i) ao perfil do Aluno, (ii) sua percepção sobre a IPES e (iii) sua relação com a mesma. A maior ênfase dos gestores nesta Dimensão demonstra a necessidade da IPES em aprofundar seu conhecimento sobre o cliente, de ouvir e entender seus anseios e expectativas, e acompanhar a sua trajetória de relacionamento com a instituição. Foi observado ainda que para uma IPES filantrópica, onde não há uma mentalidade voltada para resultados financeiros de lucratividade na relação com o cliente, este aspecto não leva a diferenciação na qualidade do atendimento prestado.

A Dimensão IES apresentou-se como a segunda de maior importância a partir das observações registradas nas entrevistas, com indicação de nove informações estratégicas relevantes. É fator crucial para a garantia de qualidade do atendimento aos clientes, não apenas conhecer o aluno, mas para conhecer a IPES e cada um de seus setores e processos. A qualificação do atendimento, com base no uso de informações da IPES e do cliente fluindo entre as ARA e os demais setores, somado à disponibilidade de informações que permita o auto-atendimento por parte do aluno, com uso de tecnologias Web, é uma verdadeira estratégia da gestão do relacionamento com o cliente (CRM).

As informações estratégicas referentes ao relacionamento da IPES e do cliente com o mercado, representadas na Dimensão Mercado com a indicação de apenas cinco informações, mostraram-se de menor relevância à instituição estudada. No entanto, apresentam-se como informações estratégicas importantes nos processos de prospecção, fidelização e análise da satisfação dos clientes da IPES. A possibilidade de acompanhamento em longo prazo do aluno, desde sua configuração como cliente potencial até a situação de ex-aluno, permite uma visão global do processo de formação e do papel da IPES. Desta maneira é possível um alinhamento entre as diretrizes estratégicas na oferta de novos produtos e serviços com as necessidades apontadas pelos seus atuais e potenciais clientes. A sobrevivência e alcance da missão institucional são assegurados a partir dos resultados da união entre os interesses dos alunos e os objetivos do planejamento estratégico de negócios e plano pedagógico da IPES (TACHIZAWA; ANDRADE, 2003). Logo, as IPES precisam refletir mais profundamente sobre seu posicionamento no mercado, tendo em vista a competitividade do setor nos últimos anos, onde o uso do CRM pode ser fundamental para definir suas estratégias de prospecção, satisfação e fidelização de alunos.

As informações estratégicas que emergiram desta pesquisa compõem um conjunto de informações básicas que uma IPES no Brasil, atualmente, necessita para iniciar um processo de implementação de CRM. Este trabalho apresenta algumas limitações em seu desenvolvimento, tais como 0 fato de que as informações coletadas nas entrevistas com os gestores das ARA estarem condicionadas às suas percepções sobre a instituição, conhecimento referente aos 
processos internos das demais ARA e visão de mercado. Tampouco foram avaliadas as opiniões dos alunos sobre as informações estratégicas resultantes da investigação. Outra limitação importante que merece destaque refere-se ao método de pesquisa, pois foi utilizado um estudo de caso único, refletindo a realidade de uma IPES filantrópica, não permitindo a generalização dos resultados encontrados para o setor ou instituições similares.

Como recomendação para futuros trabalhos fica a sugestão de que o mesmo estudo seja feito em IPES de diferentes regiões, ou mesmo em IPES com fins não filantrópicos, a fim de comparar os resultados aqui encontrados. Poder-se-ia também considerar a opinião dos atuais alunos, das empresas que os contratam para estágios ou trabalho e de alunos egressos das IPES. Para a IPES aqui estudada, se pode recomendar também um estudo que investigue a opinião dos seus alunos sobre os processos da instituição. Com os resultados destes estudos propostos seria possível obter uma visão ainda mais ampla das informações, políticas, processos e estratégias para implementação de CRM em IPES.

\section{REFERÊNCIAS}

ANDRADE, A. R. Gestão estratégica de universidades: análise comparativa de planejamento e gestão. In: XXVII ENCONTRO ANUAL DA ANPAD. Anais... Atibaia, SP, 2003.

BARDIN, L. Análise de conteúdo. Lisboa: Edições 70, 1979.

BRAGA, R. O CRM no setor educacional. Ensino Superior, São Paulo, v. 6, n. 69, p. 44-46, jun. 2004.

BRETZKE, M. Marketing de relacionamento e competição em tempo real. São Paulo: Atlas, 2000.

CARVALHO, M. H. Reengenharia comportamental aplicada as Instituições de Ensino Superior. In: FINGER, A.P. (Org.). Gestão de universidades: novas abordagens. Curitiba: Champagnat, 1997.

COOPER, D.; SCHINDLER, P. Método de Pesquisa em Administração. 7. ed. Porto Alegre: Bookman, 2003.

DORNELAS, J. S.; XAVIER, R. O. Quando o CRM será efetivo em uma empresa? In: X SIMPÓSIO DE ENGENHARIA DE PRODUÇÃO - SIMPEP. 10. ed., Anais... Bauru, SP, 2003.

FERNANDES, C. V. Qualidade total no ensino superior. Rio de Janeiro: Universidade Gama Filho, 1998.

GRANT, G. B.; ANDERSON, G. Web portals and higher education: technologies to make IT personal. In: Customer Relationship Management: a vision for higher education. Educause: Boulder-USA, $2002 . \quad$ Disponível em: < http://net.educause.edu/ir/library/pdf/pub5006o.pdf >. Acesso em 29 jun. 2008. 
HANSEN, G. L. Limites e potenciais das novas modalidades de gestão universitária. In: ALMEIDA, M. (Org.). A Universidade Possível: experiências da gestão universitária. São Paulo: Editores Associados, 2001.

INEP (INSTITUTO NACIONAL DE ESTUDOS E PESQUISAS EDUCACIONAIS ANÍSIO TEIXEIRA). Sinopse da Educação Superior. 2010. Disponível em: < http://www.inep.gov.br/superior/censosuperior/sinopse/ >. Acesso em: 29 ago. 2010.

LOPES, F. D. Teoria institucional e gestão universitária: uma análise do processo de avaliação institucional na UNIJUÍ. Revista Eletrônica da Administração. Porto Alegre: UFRGS, 12. ed., n. 4, v. 5, dez. 1999.

MEZOMO, J. C. Gestão da qualidade na escola: princípios básicos. São Paulo: Terra. 1994.

MIYASHITA, M. Relacionar-se é preciso. Revista SuperEscola, São Paulo, ano 2, n. 5, p. 12-13, jun. 2006. Disponível em: < http://miyashita.com.br/index.php?id=119\&m=82 >. Acesso em: 07 jul. 2008.

MORSOLETO, R. H. C. Educação Superior: um novo panorama. Disponível em: < http://kplus.cosmo.com.br/materia.asp?co=3\&rv=Vivencia >. Acesso em: 09 set. 2010.

OLIVEIRA, L.; RODRIGUES, C. M. C. Estudo conceitual da aplicabilidade de CRM em instituições de ensino superior. Revista Análise. Porto Alegre: PUCRS, v. 13, n. 2, 2002, 2002. p. 329-341.

PARVATIYAR, A.; SHETH, J. Customer relationship management: emerging practice, process, and discipline. Journal of Economic and Social Research, vol. 3, no. 2, 2001, 2002 Preliminary Issue, p. 1-34.

PIAZZA, M. E. O papel das coordenações de cursos de graduação segundo a percepção de coordenadores em exercício da função. 1997.213 p. Dissertação (Mestrado em Educação). Universidade Federal de São Carlos, São Carlos, 1997.

RODRIGUES, C. M. C. Proposta de avaliação integrada ao planejamento anual: um modelo para as UCGs. 2003. 341 p. Tese (Doutorado em Engenharia de Produção)Escola de Engenharia, UFRGS, Porto Alegre, 2003.

SONNEBORN, M. J. Desenvolvimento de um modelo de apoio à gestão para uma instituição de educação superior baseado em indicadores de desempenho. 2004. 116 p. Dissertação (Mestrado Profissionalizante em Engenharia de Produção)Escola de Engenharia, UFRGS, Porto Alegre, 2004.

SWIFT, R. CRM, Customer relationship management: o revolucionário marketing de relacionamentos com o cliente. Rio de Janeiro: Campos, 2001.

TACHIZAWA, T.; ANDRADE, R. O. B. Gestão de instituições de ensino. Rio de Janeiro: Fundação Getúlio Vargas, 2003. 
WINER, R. S. Customer relationship management: a framework, research directions, and the future. California Management Review. Berkeley: University of California at Berkeley, n. 43, p. 89-105, abr. 2001.

YIN, R. Estudo de caso: planejamento e métodos. 3. ed. Porto Alegre: Bookman, 2005. 
Levantamento de questões sobre cada área de atendimento ao aluno e a importância de cada um dos aspectos abordados pelas áreas:

Nome do entrevistado: atuação: ARA de

1. Há quanto tempo você trabalha nesta IES?

2. Há quanto tempo você trabalha em sua função atual?

3. Quais as principais atividades da sua área, no que tange ao atendimento ao aluno?

4. Existe na sua área um plano, estratégia ou procedimento formal para atendimento ao aluno, desenvolvido internamente ou a partir de diretrizes institucionais? Você participou do desenvolvimento deste plano?

5. Os atendentes da sua área estão cientes quanto a priorização e foco no aluno dado pela instituição? Isto se torna perceptível aos alunos?

6. Seria importante manter relacionamentos de longo prazo com os alunos, de forma controlada e reconhecida? E qual informação seria importante para este processo?

7. Busca-se de alguma forma a profissionalização das relações de trabalho no atendimento e serviços junto ao alunado?

8. As características e preferências específicas de alunos ou grupos de alunos (ex: cursos) são valorizadas no atendimento? Busca-se o conhecimento aprofundado sobre o aluno e da relação estabelecida com este?

9. Existe o entendimento do gestor sobre o aluno como gerador de lucratividade para a instituição? Este aspecto é acompanhado?

10. As informações captadas a partir do atendimento e serviços ao alunado são analisadas e utilizadas estrategicamente na sua área para a retenção e fidelização destes? E para a captação de novos alunos quando em atendimentos a comunidade?

11. Existe uma orientação visando alimentar o setor de Marketing quanto às informações captadas no atendimento ao aluno?

12.Sua área provê informações relevantes para a tomada de decisões quanto ao lançamento de novos serviços?

13. As ações de sua área frente ao alunado são caracteristicamente reativas ou próativas (em manter o diálogo com o aluno)?

14.É acompanhado o processo de evasão de alunos da instituição a fim de reduzir seu percentual?

15. As informações sobre os hábitos dos alunos, fatores culturais, sociais e econômicos são considerados no atendimento aos mesmos?

16. Que outras informações sobre o aluno ou o negócio são estratégicas para o atendimento na sua área, buscando a satisfação, fidelização e retenção do aluno, de forma alinhada as diretrizes, objetivos e valores institucionais?

17. Que outras informações são estratégicas para o atendimento na sua área, buscando a captação de novos alunos, de forma alinhada as diretrizes, objetivos e valores institucionais?

18. Existe uma preocupação quanto a privacidade do aluno e de suas informações no atendimento? 
19. Busca-se a padronização de trabalho e atendimento entre as diversas áreas, procurando a otimização e qualificação de processos e resultados?

20. Existem estratégias claras para sua área para a retenção do aluno na instituição? E para a captação de novos alunos?

21. Existem indicadores para o acompanhamento e medição no atendimento ao aluno, quanto a qualidade do atendimento, tempo de atendimento, agilidade, atualização, satisfação e fidelidade do aluno?

22. Existem metas específicas para estes indicadores no atendimento ao aluno?

23. São realizadas ações coordenadas com outras áreas de atendimento na instituição?

24. Quais informações da sua área poderiam auxiliar o desempenho de atendimento ao aluno em outras áreas? Através de qual processo?

25. Quais informações de outras áreas poderiam auxiliar no desempenho de atendimento ao aluno da sua área? Como obtê-las?

26. Como você avalia os benefícios que a tecnologia da informação pode oferecer à universidade, com respeito ao atendimento ao aluno? Por quê?

27. Como você avalia a sua área com relação ao atendimento aos alunos? Ótima, boa, média, ruim, péssima. Por quê?

28. Qual a sua avaliação geral, sobre atendimento ao aluno, da universidade? Por quê? 